\title{
Alpha-fetoprotein concentrations measured by radioimmunoassay in diagnosing and excluding hepatocellular carcinoma
}

\author{
P J JOHNSON， B PORTMANN， ROGER WILLIAMS
}

British Medical fournal, 1978, 2, 661-663

\section{Summary and conclusions}

Serum $\alpha$-fetoprotein (AFP) concentrations were estimated by sensitive radioimmunoassay in 30 patients with cirrhosis complicated by hepatocellular carcinoma and in 100 patients with cirrhosis in whom malignancy was excluded. Twenty-nine of the 30 patients with hepatocellular carcinoma had concentrations above $10 \mathrm{IU} / \mathrm{ml}(10.5 \mathrm{ng} / \mathrm{ml})$ (median $3500 \mathrm{IU} / \mathrm{ml}(3675 \mathrm{ng} / \mathrm{ml})$ ), whereas only one of the 100 patients with cirrhosis and no tumour development had a raised concentration. Eleven out of 20 patients in whom hepatocellular carcinoma had developed in an apparently normal liver had raised AFP concentrations. In this group the differential diagnosis is usually secondary carcinoma, and three of 50 such patients had AFP concentrations above $10 \mathrm{IU} / \mathrm{ml}$.

Noting raised AFP concentrations is thus of considerable value both in detecting and in excluding hepatocellular carcinoma in cirrhosis, for in this case such concentrations gave only $1 \%$ false-positive and $3 \%$ falsenegative results. They are less useful, however, in distinguishing between primary tumours arising in patients without cirrhosis and secondary hepatic deposits, giving $6 \%$ false-positive and $45 \%$ false-negative results.

\section{Introduction}

The detection of $\alpha$-fetoprotein (AFP) in serum by the simple immunodiffusion technique is a reliable test for hepatocellular carcinoma, being positive in $71-87 \%$ of cases in parts of Africa and the Far East, where the prevalence of this tumour is high. ${ }^{1-3}$ In Britain, where the prevalence is much lower, only $29-38 \%$ of cases show positive results. ${ }^{45}$ Several recent studies, however, have shown that concentrations in about two-thirds of patients who were AFP-negative by immunodiffusion could be detected by more sensitive techniques. ${ }^{6}$ Concentrations of up to $20 \mathrm{IU} / \mathrm{ml}(21 \mathrm{ng} / \mathrm{ml})$ may be found in normal subjects, ${ }^{8}{ }^{9}$ although because of the difficulty in accurately measuring such low concentrations, the lack of an acceptable AFP standard, and the finding of marginally raised concentrations in non-hepatic diseases, most workers have considered only concentrations above about $50 \mathrm{IU} / \mathrm{ml}(53 \mathrm{ng} / \mathrm{ml})$ to be abnormal. Furthermore, higher concentrations may be found in between $1 \%{ }^{10}$ and $44 \%^{11}$ of patients with chronic liver diseases and in about $10 \%$ of patients with other malignant neoplasms, ${ }^{12}$ suggesting that as more sensitive assays were developed there was a concomitant loss of specificity. The

Liver Unit, King's College Hospital and Medical School, Denmark Hill, London SE5

P J JOHNSON, MB, MRCP, research fellow

B PORTMANN, MD, MRCPATH, consultant histopathologist

ROGER WILLIAMS, MD, FRCP, director and consultant physician possibility that raised AFP concentrations in chronic liver disease represent occult hepatocellular carcinoma rather than falsepositive results has not been fully excluded.

In the present study the reliability of quantitative estimation of AFP concentrations by radioimmunoassay in the early diagnosis of hepatocellular carcinoma in cirrhosis was assessed prospectively in 50 consecutive British patients with hepatocellular carcinoma, 30 with and 20 without underlying cirrhosis. One hundred patients with cirrhosis in whom malignancy was excluded and 50 patients with secondary tumours arising in a non-cirrhotic liver were also investigated as control groups.

\section{Patients and methods}

Fifty patients with histologically confirmed primary hepatocellular carcinoma were investigated at diagnosis. Patients with other primary hepatic tumours, such as cholangiocarcinoma and haemangiosarcoma, were excluded from the study. Thirty patients, all men aged 53-74 years, had developed the tumour on the basis of underlying cirrhosis. In the other 20 cases (11 men and nine women, aged 27-72 years) the tumour had arisen in an otherwise normal liver. Fifty patients with secondary deposits in the liver from various primary neoplasms (see table) were also studied at the time of clinical presentation.

Sera from 85 of the 100 patients in the final group with histologically confirmed cirrhosis, on whom necropsy had been carried out during 1975-7 but in whom there was no evidence of malignant change, were obtained from the unit's serum bank. In each case the serum had been collected within six months of the patient's death. The types of cirrhosis were classified on the basis of the recorded clinical and histological features as cryptogenic ( 25 cases), alcoholic cirrhosis (25), chronic active hepatitis (20), and primary biliary cirrhosis (15). The remaining 15 patients in this control group had haemochromatosis and are still alive. They were carefully followed up over two years and showed no clinical evidence of tumour development. These patients were included because of the apparently high risk of the development of hepatoma in haemochromatosis.

AFP concentrations were estimated using a sensitive radioimmunoassay technique capable of detecting concentrations of $2 \mathrm{IU} / \mathrm{ml}(2 \cdot 1 \mathrm{ng} / \mathrm{ml})$. In contrast, positive results with the immunodiffusion technique may be obtained only at concentrations above about $5000 \mathrm{IU} / \mathrm{ml}(5250 \mathrm{ng} / \mathrm{ml}) .{ }^{13}$ All samples were run in duplicate, and in those in which the concentration was above normal (as established from 50 healthy controls from the unit staff) the assay was repeated at least once.

\section{Results}

AFP concentrations in the 50 healthy controls were all below $10 \mathrm{IU} / \mathrm{ml}(10.5 \mathrm{ng} / \mathrm{ml})$, and concentrations above this were therefore considered to be abnormal and the sera referred to as AFP-positive.

Site of primary tumour in the 50 patients with hepatic metastases, and number with raised $\alpha$-fetoprotein $(A F P)$ concentration

\begin{tabular}{l|c|c}
\hline \multicolumn{1}{c|}{$\begin{array}{c}\text { Site of primary } \\
\text { tumour }\end{array}$} & $\begin{array}{c}\text { No of } \\
\text { patients }\end{array}$ & $\begin{array}{c}\text { No with raised AFP } \\
\text { concentration }\end{array}$ \\
\hline Bronchus & 12 & 2 \\
Breast & 10 & 1 \\
Pancreas & 10 & \\
Colon & 7 & \\
Stomach & 3 & \\
Other & 8 & \\
\hline
\end{tabular}


Twenty-nine $(97 \%)$ of the 30 patients with cirrhosis and hepatocellular carcinoma had AFP-positive sera (range of concentrations 110-508 $000 \mathrm{IU} / \mathrm{ml}(116-533400 \mathrm{ng} / \mathrm{ml})$; median $3500 \mathrm{IU} / \mathrm{ml}$ $(3675 \mathrm{ng} / \mathrm{ml}))$. Of the 100 control patients with cirrhosis, only one had a slightly raised AFP concentration $(28 \mathrm{IU} / \mathrm{ml}(29.4 \mathrm{ng} / \mathrm{ml}))$; in all other cases concentrations were below $10 \mathrm{IU} / \mathrm{ml}$ (see fig). The 97\% positivity in the patients with cirrhosis and hepatocellular carcinoma was compared with the $55 \%$ positivity (11 of 20 cases) in

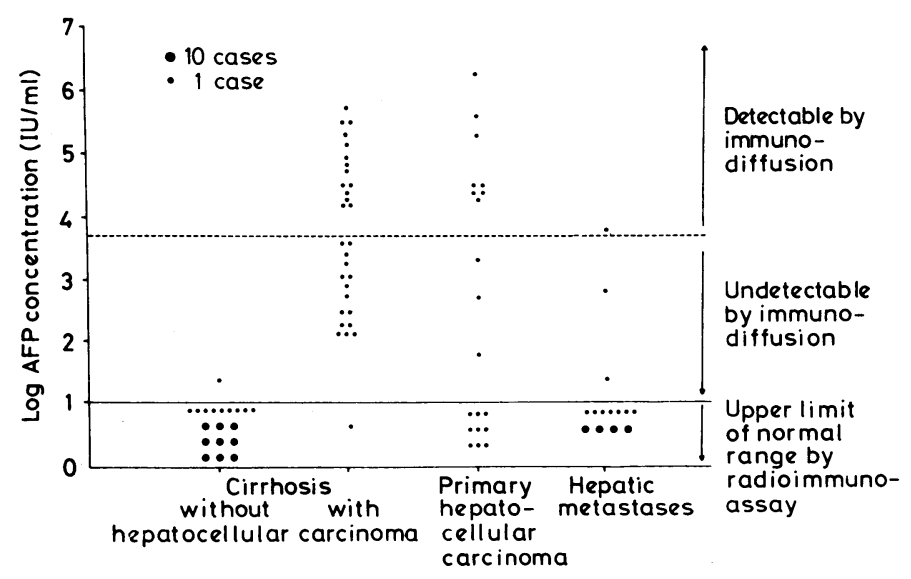

AFP concentrations in the four groups investigated-namely, patients with cirrhosis but without hepatocellular carcinoma; with cirrhosis and hepatocellular carcinoma; with primary hepatocellular carcinoma but without cirrhosis; and with hepatic metastases only. Concentrations in 50 healthy controls were below $10 \mathrm{IU} / \mathrm{ml}(10.5 \mathrm{ng} / \mathrm{ml})$.

the patients with hepatocellular carcinoma in an otherwise normal liver. The difference was highly significant $(P<0.001)$. Such a difference would not have occurred using the immunodiffusion technique since detection of the 15 patients with cirrhosis and hepatocellular carcinoma who had concentrations of $20-5000 \mathrm{IU} / \mathrm{ml}(21-5250 \mathrm{ng} / \mathrm{ml})$ would not have been possible. Indeed, the incidences of positive sera found with the immunodiffusion technique for patients with and without underlying cirrhosis would have been $47 \%$ and $40 \%$ respectively.

Three $(6 \%)$ of the 50 patients with secondary liver cancer had concentrations above $10 \mathrm{IU} / \mathrm{ml}$. The sites of the primary tumours (and the AFP concentrations) in these cases were bronchus $(600 \mathrm{IU} / \mathrm{ml}(630 \mathrm{ng} / \mathrm{ml}))$, pancreas $(6280 \mathrm{IU} / \mathrm{ml}(6594 \mathrm{ng} / \mathrm{ml}))$, and bronchus (35 $\mathrm{IU} / \mathrm{ml}(37 \mathrm{ng} / \mathrm{ml})$ ).

\section{Discussion}

Our results show that with radioimmunoassay the incidence of raised AFP concentrations in patients with hepatocellular carcinoma in Britain $(80 \%)$ is similar to that found in highincidence areas with the immunodiffusion technique. Kohn et $a l^{13}$ also reported that AFP concentrations in $83 \%$ of sera referred to them from Caucasian patients with hepatocellular carcinoma were raised when measured by radioimmunoassay, which has been found in other areas of low incidence such as Scandinavia. ${ }^{14}$ Since over $80 \%$ of cases in high-incidence areas are AFP-positive by immunodiffusion alone, however, clearly the absolute concentrations of AFP must be generally higher than those found in patients from Britain. This may be a reflection of the rapid clinical course of the disease in highincidence areas. It has been suggested that other factors such as age, sex, and histological appearance of the tumour might also influence AFP concentrations, but in no case has a close correlation been shown. ${ }^{214-16}$

Although most workers have failed to detect any difference in AFP positivity between those patients who develop hepatocellular carcinoma on the basis of cirrhosis and those in whom the underlying liver is normal, 1417 this again reflects the insensitivity of the immunodiffusion technique. The present findings have shown that the incidence of AFP positivity with radioimmunoassay is clearly higher in patients with underlying cirrhosis. Whether cases of AFP-negative hepatocellular carcinoma are a clinical entity representing malignant transformation of a specific subgroup of hepatocytes is not known. It is our clinical impression that the prognosis in this group may be better, although possibly this reflects merely the much greater chance of successful treatment by surgery and the larger functional reserve when the underlying liver is normal rather than cirrhotic. ${ }^{18}$

The frequency with which raised AFP concentrations are detected in patients with metastatic liver disease depends on the origin of the primary tumour, as it is well recognised that neoplasms of the gastrointestinal tract, particularly those of the stomach and pancreas, are most likely to secrete AFP. ${ }^{19}$ In an analysis of the results of six series Alpert found that $8.6 \%$ of cases had AFP concentrations above $50 \mathrm{IU} / \mathrm{ml}(52.5 \mathrm{ng} / \mathrm{ml})$, and our figure of $6 \%$ agrees with this. ${ }^{12}$ Our series was typical of the type of metastatic liver disease seen in this country, in which primary tumours occur mainly in the lung, pancreas, colon, and breast. In general AFP concentrations are higher in patients with primary tumour, and values above $1000 \mathrm{IU} / \mathrm{ml}$ $(1050 \mathrm{ng} / \mathrm{ml})$ strongly indicate this diagnosis rather than secondary carcinoma. On the other hand, concentrations below $1000 \mathrm{IU} / \mathrm{ml}$ in patients without cirrhosis are of little value in distinguishing between primary and secondary liver cancer.

While some workers have, as in our case, found that only about $1 \%$ of patients with cirrhosis have raised AFP concentrations, ${ }^{10} 20$ others have reported higher incidences-namely, $15 \%,{ }^{14} 47 \%{ }^{6}$ and $12 \%{ }^{21}$ One possibility to account for these differences is that some of the AFP-positive patients had undetectable tumour, and indeed four of 10 patients with cirrhosis reported by Eleftheriou et al as having AFP concentrations above $20 \mathrm{IU} / \mathrm{ml}(21 \mathrm{ng} / \mathrm{ml})$ were subsequently found to have developed hepatocellular carcinoma. ${ }^{21}$ In chronic active hepatitis it is the patients with "active" disease based on histological and biochemical criteria ${ }^{62}$ who have raised AFP concentrations, whereas at the later cirrhotic and inactive stages, as in the present series, the incidence of AFP positivity is lower. Malignant transformation is seldom an important differential diagnosis in the early stages of chronic active hepatitis, usually occurring when the patient has had cirrhosis for several years. ${ }^{23}$ It should be emphasised that AFP concentrations above $10 \mathrm{IU} / \mathrm{ml}$ $(10.5 \mathrm{ng} / \mathrm{ml})$ are diagnostic of hepatocellular carcinoma only in patients known to have cirrhosis. Concentrations up to $500 \mathrm{IU} / \mathrm{ml}$ $(5250 \mathrm{ng} / \mathrm{ml})$ have been found in patients with acute hepatitis, ${ }^{24}$ and concentrations up to $100 \mathrm{IU} / \mathrm{ml}(105 \mathrm{ng} / \mathrm{ml})$ may occur in conditions as varied as congestive cardiac failure and chronic lymphatic leukaemia. ${ }^{25}$

If the AFP concentration is only slightly raised in a patient with cirrhosis who is otherwise asymptomatic further measurement at monthly intervals should help to resolve the problem, since a continuous rise in AFP concentrations is likely to be of serious significance. A diagnosis should be established and treatment initiated at this stage rather than after a later, rapid rise in AFP concentration. This, according to evidence from cases occurring in this country ${ }^{26}$ and Japan, ${ }^{27}$ precedes the onset of symptoms and usual time of diagnosis by only a few months, by which time the tumour is almost invariably of considerable size.

Dr P J Johnson was supported by the Saltwell Research Fellowship of the Royal College of Physicians. The National Institute for Biological Standards and Control supplied the 1st British Standard for Human Cord Serum (72/227). We are also grateful to the Cancer Research Campaign for financial support and to Linda Rimmer for editorial help.

\section{References}

1 O'Conor, G T, et al, Cancer, 1970, 25, 1091.

2 Purves, L R, Bersohn, I, and Geddes, E W, Cancer, 1970, 25, 1261.

${ }^{3}$ Kresno, S, Gandasoebrata, K, and Rumke, P, Lancet, 1970, 1, 1178. 
4 Foli, A K, Sherlock, S, and Adinolfi, M, Lancet, 1969, 2, 1267.

5 Kew, M C, Dos Santos, H A, and Sherlock, S, British Medical fournal, $1971,4,408$.

6 Ishii, M, Gann. Monographs of Cancer Research, 1973, 14, 89.

7 McIntire, K R, et al, Cancer Research, 1972, 32, 1941.

${ }^{8}$ Ruoslahti, E, and Seppala, M, Nature, 1972, 235, 161.

${ }^{9}$ Purves, L R, et al, Cancer, 1973, 31, 578.

10 Abelev, G I, Advances in Cancer Research, 1971, 14, 295.

11 Hirai, H, Nishi S and Watabe, H, Protides of the Biological Fluids, 1973, 20, 579.

${ }^{12}$ Alpert, E, in Hepatocellular Carcinoma, ed K Okuda and R L Peters. New York, Wiley, 1976.

13 Kohn, J, and Weaver, P C, Lancet 1974, 2, 334.

14 Ruoslahti, E, Salaspuro, M, and Pihko, H, British Medical fournal, 1974, 2, 527.
15 Mawas, C, Buffe, D, and Burtin, P, Lancet, 1970, 1, 1292.

16 Bagshawe, A, and Parker, A M, Lancet, 1970, 2, 268.

17 Alpert, E, et al, Gastroenterology, 1971, 61, 137.

18 Johnson, P J, Portmann, B, and Williams, R, unpublished observations.

19 McIntire, K R, et al, Cancer Research, 1975, 35, 991.

${ }_{20}$ Alpert, E, National Cancer Institute Monographs, 1972, 35, 415.

${ }^{21}$ Eleftheriou, N, et al, fournal of Clinical Pathology, 1977, 30, 704.

${ }^{22}$ Silver, H K B, et al, New England fournal of Medicine, 1974, 291, 506.

${ }^{23}$ Johnson, $\mathrm{P} \mathrm{J}$, et al, Gut, in press.

${ }^{24}$ Smith, J H, International fournal of Cancer, 1971, 8, 421.

${ }^{25}$ Howarth, C, and Johnson, $\mathrm{P}$ J, unpublished observations.

${ }^{26}$ Johnson, P J, and Williams, R, unpublished observations.

${ }^{27}$ Okuda, K, et al, Gastroenterology, 1975, 69, 226.

(Accepted 14 fuly 1978)

\section{SHORT REPORTS}

\section{Cardiovascular health in the tenth decade}

Death from ischaemic heart disease is the most important single killer in western societies, and several so-called coronary risk factors have been delineated. Although numerous studies have been performed on the association between those factors and death from ischaemic heart disease, remarkably little is known about the inverse relationship: have people who nowadays live unusually long in apparently good health shown few coronary risk factors during life ? Or is their longevity determined familially? We therefore studied a group of elderly healthy people (90 years or older). ${ }^{1}$

\section{Patients, methods, and results}

A total of 100 apparently healthy Dutch nonagenarians, 50 men and 50 women, was randomly recruited from two Amsterdam homes for the aged. The study consisted of a detailed biographical, medical, and nutritional interview; physical examination; ECG; chest roentgenogram; and blood biochemical tests. To exclude familial factors the authenticated life span of their parents was compared with that of the parents of a control group, born in the same period and taken at random from the Amsterdam birth registers.

The occupational history showed that most of them had worked vigorously for over 55 years and that they belonged to the lower social class. Hypertension had been diagnosed in $19 \%$, mostly in the past ten years and in the great majority because of a raised systolic blood pressure. Diabetes mellitus was present in eight people, two of whom received insulin. Their smoking habits were most remarkable: only $2 \%$ had smoked more than the occasional cigarette; generally the women had never smoked and the men only a few cigars a day. Serious overweight (more than $30 \%$ above ideal weight) was also infrequent, especially among the men. Cardiovascular disease was found in 28 subjects: seven had had myocardial infarction, four had angina pectoris, 14 had had symptoms of congestive heart failure, and three had an artificial pacemaker because of chronic atrioventricular block. Analysis of their diets showed that they had all eaten relatively little, but had taken the same relative amounts of proteins, carbohydrates, total fat, polyunsaturated fat, and cholesterol as the total Dutch population.

The difference between the life span of the nonagenarians' parents and that of the controls' parents was not significant (Wilcoxon's distribution free test for survival tables $P>0 \cdot 10$ ). Some data on their current health are given in the table. The ECG was abnormal in $87 \%$, conduction disturbances being present in half.

\section{Comment}

Longevity may result either from nature or from nurture. Our genealogical findings did not show a major familial influence: there was only a weak positive relationship between the parents' age at death and the current age of their children, a result similar to that found in more extensive studies. ${ }^{2}$ Where the role of nature seems small the role of nurture has attracted much interest, and among nonagenarians one would expect an absence of coronary risk factors, which are associated with a large part of all causes of death.

Hypertension had been diagnosed frequently in the histories of many of the subjects, but the criteria were not clear and probably
Some physical and biochemical data in 50 men and 50 women who were healthy nonagenarians

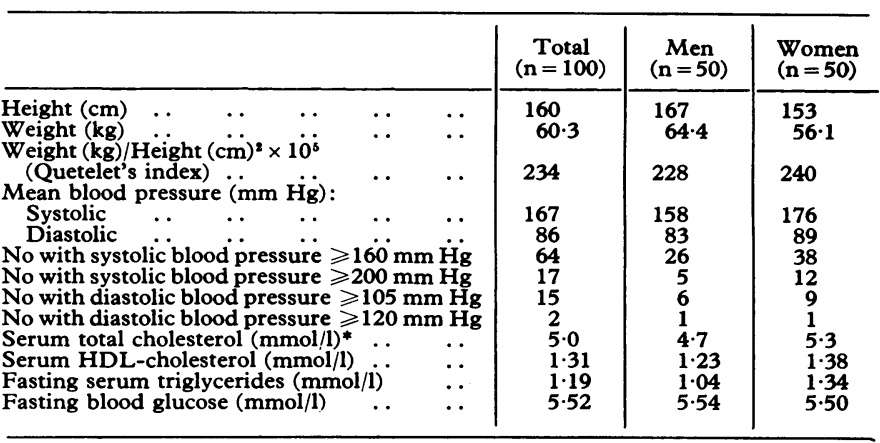

*Determined according to Abell-Kendall's method.

Conversion: SI to traditional units-Cholesterol: $1 \mathrm{mmol} / 1 \approx 38.6 \mathrm{mg} / 100 \mathrm{ml}$ Triglycerides: $1 \mathrm{mmol} / 1 \approx 88.5 \mathrm{mg} / 100 \mathrm{ml}$. Glucose: $1 \mathrm{mmol} / 1 \approx 18 \mathrm{mg} / 100 \mathrm{ml}$.

merely a rise in systolic pressure had usually led to the diagnosis. On examination the mean systolic pressure was raised, but the diastolic pressure equalled that reported in most population studies of western middle-aged people. Few people smoked, even given their social and cultural background. ${ }^{3}$ Unfortunately we could trace no data on lipid values in previous years but the current total cholesterol concentration was very low, especially in men; high density lipoprotein (HDL) cholesterol was normal-that is, in the same range as in several population studies. A low total cholesterol and a normal HDL cholesterol give a high HDL:total cholesterol ratio, an interesting finding in view of a possible anti-atherogenic role of HDL. ${ }^{5}$ One of the key questions that arises is whether the lipid pattern found in these people is the result of aging or represents selection-the survival of people with favourable lipid values. Only longitudinal follow-up of large series of people living to a great age can answer this.

Despite the shortcomings of a small and retrospective study such as this, we conclude that in many respects the coronary risk profile of these apparently healthy nonagenarians represents the mirror image of that of the contemporary coronary-prone middle-aged adult.

1 Danner, S A. Thesis, University of Amsterdam, 1977.

2 Abbott, M H, et al, Bulletin of the fohns Hopkins Hospital, 1974, 134, 1.

3 van Zonneveld, R J, The Health of the Aged. Assen, van Gorcum, 1961.

4 Castelli, W P, et al, Fournal of Chronic Diseases, 1977, 30, 147.

5 Miller, G J, and Miller, N E, Lancet, 1975, 1, 16.

(Accepted 19 fune 1978)

University Department of Medicine, Binnengasthuis, Amsterdam,

The Netherlands

SVEN A DANNER, MD, consultant physician

MARIE-JOSEEE DE BEAUMONT, social worker

AREND J DUNNING, MD, lecturer 